\title{
GRAND DESIGN PENGEMBANGAN TEKNOLOGI INFORMASI \& KOMUNIKASI (TIK) UNIVERSITAS ASAHAN
}

\author{
Adi Widarma \\ Program Studi Teknik Informatika, \\ Fakultas Teknik Universitas Asahan \\ Jl. Jend. Ahmad Yani, Kisaran 21216, Sumatera Utara \\ adiwidarma@una.ac.id
}

\begin{abstract}
Abstrak- Perkembangan teknologi informasi dan komunikasi (TIK) tidak terlepas dari perkembangan software (perangkat lunak) dan hardware (perangkat keras). Efisiensi waktu dan kemudahan akses memberikan dampak yang positif akibat perkembangan TIK di tengah-tengah kehidupan masyarakat. Dunia pendidikan khususnya perguruan tinggi seperti Universitas Asahan harus mengikuti dan menerapkan TIK untuk dapat memberikan layanan kepada civitas akademika dan stakeholder nya agar bisa bersaing antar perguruan tinggi. Pengembangan TIK di Universitas Asahan dilakukan dengan membuat Grand Design berupa perencanaan infrastruktur server dan jaringan, perencanaan sistem informasi dan aplikasi berbasis web. Untuk dapat menerapkan rencana strategi pengembangan tersebut, dilakukan dengan menggunakan metode yang dibuat oleh James Martin metodologi renstra SI yang berbasiskan Information Engineering. Hasil dari penelitian ini yaitu mendapatkan Grand Design dan kemudian bisa menjadi rujukan pimpinan dalam mengembangkan TIK di Universitas Asahan.
\end{abstract}

Kata Kunci- Grand Design, teknologi informasi \& komunikasi, rencana strategi

\section{PENDAHULUAN}

Perkembangan yang sangat pesat saat ini adalah perkembangan dunia teknologi informasi yang tidak terlepas dari perkembangan perangkat lunak, perangkat keras, jaringan internet bahkan telekomunikasi. Dalam hal perkembangan teknologi informasi ini, segala sesuatu pekerjaan lebih mudah untuk dikerjakan. Sehingga akan membuat masyarakat lebih cepat dalam hal mendapatkan informasi. Efisiensi waktu dan kemudahan akses juga memberikan dampak yang positif terhadap perkembangan teknologi informasi.

Pemanfaatan teknologi informasi sangat besar sekali pengaruhnya terhadap perkembangan didalam segala sektor, baik sektor ekonomi, sektor industri, sektor pemerintahan bahkan juga didalam sektor dunia pendidikan.

Didalam sektor pendidikan khususnya perguruan tinggi, teknologi informasi merupakan hal yang amat sangat penting keberadaannya didalam mendukung pembelajaran dan menjadikan universitas unggul dalam persaingan didalam mengelola perguruan tinggi. Persaingan yang sehat dan menciptakan suasana harmonis antar perguruan tinggi merupakan cita-cita seluruh perguruan tinggi untuk mendidik dan mencerdaskan pemuda masa depan bangsa. Dengan adanya teknologi informasi diyakini akan mampu mengubah cara kerja yang konvensional, proses kerja administrasi yang berbelit-belit juga membutuhkan waktu yang lama sehingga segala layanan akan terkendala dan citra universitas akan tidak baik didalam pandangan masyarakat.
Persaingan kompetitif antar perguruan tinggi juga sangat ketat. Untuk memberikan perhatian yang lebih terhadap masyarakat haruslah memberikan layanan yang terbaik. Pemanfatan teknologi informasi diyakini bisa mendukung layanan menjadikan proses akan memjadi efisien, transparan dan efektif. Namun dalam hal membangun teknologi informasi bukan hanya sekedar menjalankan proses yang secara rutin dilakukan, tetapi menjadikan aliran proses informasi secara sistematis dan terintegrasi sehingga menjadi suatu sistem yang terpadu.

Perkembangan teknologi informasi tidak bisa terlepas dari perkembangan infrastruktur didalamnya. Saat ini, Universitas Asahan sudah memiliki jaringan LAN lokal di tiap-tiap unit dan sudah bisa akses internet. Masing-masing unit masih memiliki jaringan internet sendiri, dan juga mengembangkan sistem informasi sendiri tanpa adanya koordinasi, akibatnya akan menimbulkan adanya duplikasi data dan tidak terintegrasi nya sistem menjadi satu kesatuan yang terpadu serta memiliki server yang space nya masih rendah. Walaupun infrastruktur didalamnya sudah ada, tetapi Universitas Asahan belum memiliki dokumen perancanaan (grand desain) pengembangan teknologi informasi dan sistem informasi yang mencakup seluruh unit sehingga hasilnya belum optimal. 


\section{KAJIAN TEORI}

A. Pengertian Teknologi Informasi dan Komunikasi Menurut Puskur Diknas Indonesia, Teknologi Informasi dan Komunikasi mencakup dua aspek, yaitu Teknologi Informasi dan Teknologi Komunikasi. Teknologi Informasi adalah meliputi segala hal yang berkaitan dengan proses, penggunaan sebagai alat bantu, manipulasi, dan pengelolaan informasi. Teknologi Komunikasi adalah segala hal yang berkaitan dengan penggunaan alat bantu untuk memproses dan mentransfer data dari perangkat yang satu ke lainnya. Sedangkan Menurut Eric Deeson: Teknologi informasi dan Komunikasi adalah kebutuhan manusia didalam mengambil dan memindahkan, mengolah dan memproses informasi dalam konteks sosial yang menguntungkan diri sendiri dan masyarakat secara keseluruhan. ${ }^{[1]}$

\section{B. Peranan Teknologi Informasi dan Komunikasi dalam Perguruan Tinggi}

Peranan teknologi informasi dan komunikasi sangat terasa sekali keberadaannya di tengah-tengah kehidupan masyarakat pada saat sekarang ini. Mudah dan cepat mendapatkan informasi merupakan peran dari perkembangan teknologi informasi dan komunikasi. Dunia pendidikan khususnya perguruan tinggi juga merasakan akibat dari perkembangan teknologi informasi dan komunikasi. Beberapa perguruan tinggi baik negeri maupun swasta sudah memanfaatkan teknologi informasi dan komunikasi dalam kegiatan akademik mahasiswanya. Sehingga pemanfaatan teknologi informasi dan komunikasi untuk setiap aktifitas internal dalam perguruan tinggi akan menjadi faktor kesuksesan dan kemajuan dari perguruan tinggi tersebut.

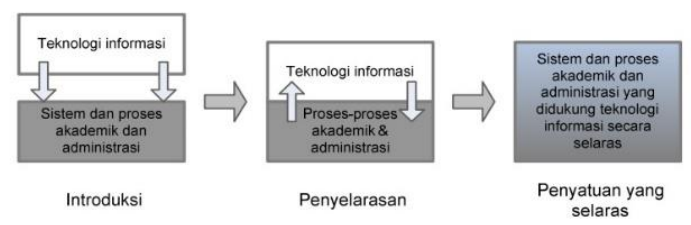

Gbr 1. Pencampuran yang selaras antara penerapan teknologi informasi dengan sistem dan proses di perguruan tinggi. ${ }^{[6]}$

\section{Information Engineering (IE) versi James Martin}

Metode Information Engineering merupakan sebuah pendekatan untuk perencanaan, analisis, dan implementasi suatu aplikasi dalam suatu perusahaan, yang bertujuan untuk memungkinkan suatu perusahaan untuk meningkatkan sumber dayanya termasuk modal, kualitas SDM dan Sistem Informasi. Hal ini berguna untuk mendukung visi bisnis perusahaan. Metode Information Engineering sudah mulai dikembangkan dari tahun 1976 oleh James Martin dan diterbitkan dalam bentuk literatur pada tahun 1981. Metode ini terdiri dari empat lapisan (Martin, 1990). Empat lapisan tersebut bisa dilihat pada gambar berikut.

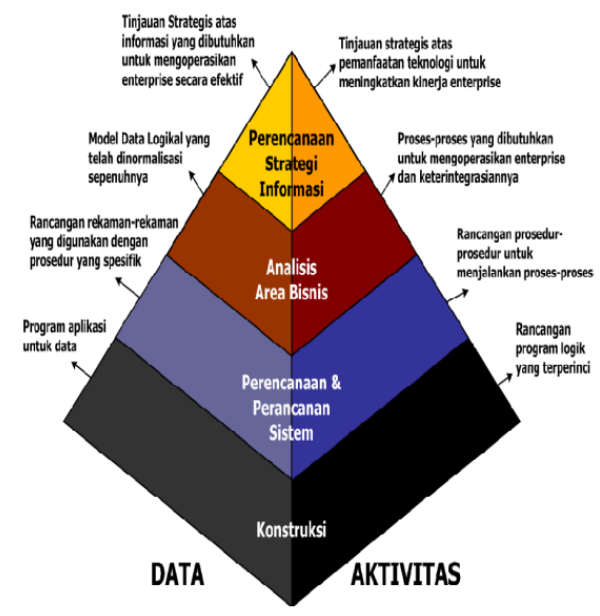

Gbr 2. Information Engineering (IE) Versi James Martin ${ }^{[5]}$

Penjelasan dari masing-masing lapisan metode Information Engineering versi James Martin adalah sebagai berikut (Martin, 1990).

a. Perencanaan strategi informasi (information strategic planning) merupakan tinjauan strategis atas informasi dan pemanfaatan sistem informasi dan teknologi pada seluruh bagian dalam organisasi untuk perencanaan terhadap masa depan, sehingga dapat meningkatkan kinerja organisasi.

b. Analisis area bisnis (business area analysis). Pada lapisan ini akan menghasilkan suatu model data dan model proses dari area bisnis yang dianalisis.

c. Perancangan sistem (system design). Pada lapisan ini digunakan alat bantu otomatis (automated tools) yang dapat menunjukkan jenis informasi apa saja yang dapat digunakan pada lapisan ini.

d. Lapisan konstruksi (construction). Berdasarkan rancangan yang sudah dibuat pada lapisan atasnya sistem dibangun dengan menggunakan automated code generator

\section{METODE PENELITIAN}

Dalam penelitian ini digunakan teknik renstra dalam IBM Bussiness Strategic Planning(BSP) dan metodologi renstra SI yang berbasiskan Information Engineering (ibid) yang dibuat oleh James Martin. Metode renstra SI James Martin terdiri dari dua tahap, yaitu analisis dan perancangan.

1. Tahapan Analisis

Dalam tahap analisis, kegiatan yang dilakukan sebagai berikut.

a. Tinjauan model perusahaan;

b. Analisis strategi bisnis; 
c. Analisis sasaran dan masalah;

d. Analisis CSF;

e. Analisis dampak teknologi;

f. Pandangan strategis sistem;

g. Analisis evaluasi sistem yang telah ada.

Page | 107 2. Tahapan Perancangan

Dalam tahap perancangan, kegiatan yang dilakukan berupa berikut ini.

a. Pembuatan arsitektur informasi;

b. pembuatan matriks fungsional;

c. pembuatan jaringan komunikasi infrastruktur dan aturan yang disesuaikan dengan hasil analisis guna kepentingan implementasi saat ini dan mendatang;

d. pembuatan ERD berdasarkan hubungan fungsional/entitas guna pengembangan basis data/aplikasi sesuai dengan objective organisasi.

Tahapan-tahapan tersebut dapat digambarkan seperti gambar dibawah ini dalam penyusunan Grand Design Universitas Asahan.

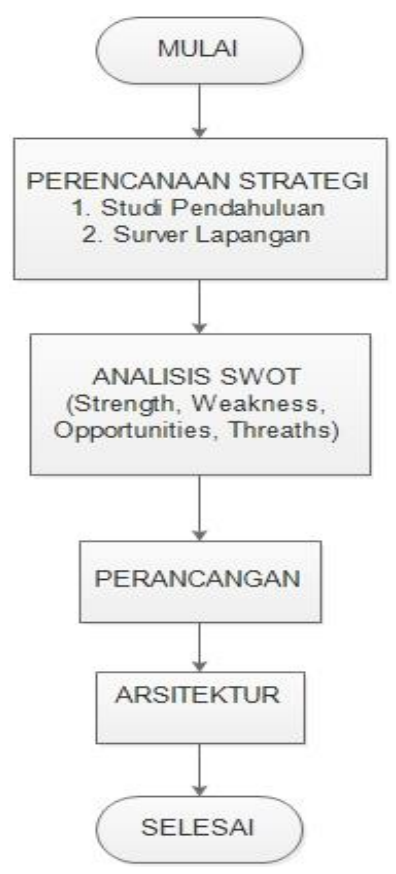

Gbr 3. Tahapan Penyusunan Grand Design TIK Universitas Asahan

\section{IV.HASIL DAN PEMBAHASAN}

A. Identifikasi masalah pada infrastruktur di Universitas Asahan

Universitas Asahan sudah terpasang jaringan lokal, tetapi tidak semua unit terpasang jaringan untuk bisa akses sistem informasi. Dari jumlah 12 gedung yang ada hanya 9 gedung yang sudah memiliki akses internet. Walaupun sudah ada akses internet tetapi pemasangan jaringan internet tidak terpusat ke satu titik. Masing-masing gedung memiliki akses internet tersendiri sehingga untuk memanajemen sangatlah sulit dan juga membuat distribusi data tidak terpusat.

Universitas Asahan memiliki website universitas dan fakultas yang selama ini masih hosting diluar sehingga akses intranet tidak berjalan. Terdapat server lokal untuk akses akademik dimana spesifikasi server tersebut kurang memadai untuk diakses banyak client.

Berikut adalah beberapa permasalahan pada infrastruktur untuk menjalankan teknologi informasi dan komunikasi di Universitas Asahan:

1. Spesifikasi server untuk tempat hosting website dan aplikasi kurang memadai.

2. Pemanfaaatan Infrastruktur pada jaringan kurang optimal

3. Infrastruktur jaringan tidak termanajemen dan tidak memiliki sistem keamanan jaringan

4. Akses jaringan nirkabel (wifi) tidak mengcover seluruh ruangan di unit-unit.

5. Terbatasnya SDM yang mengelola infrastruktur seperti network administrator dan teknisi komputer.

B. Identifikasi masalah pada perangkat lunak sistem informasi di Universitas Asahan

Website Universitas Asahan yaitu una.ac.id, dan ada 5 website fakultas yaitu fakultas teknik memiliki website ft.una.ac.id, fakultas ekonomi yaitu fe.una.ac.id, fakultas hukum yaitu fh.una.ac.id, fakultas pertanian yaitu fper.una.ac.id dan fakultas keguruan yaitu fkip.una.ac.id. Selain itu ada beberapa aplikasi yang terdapat di Universitas Asahan yaitu aplikasi akademik, aplikasi jurnal, aplikasi feeder dikti.

Berikut adalah permasalahan pada perangkat lunak sistem informasi Universitas Asahan:

1. Sistem informasi berupa website tidak memberikan informasi kepada civitas akademika Universitas Asahan karena content website tersebut tidak terupdate.

2. Aplikasi web akademik belum memberikan peran nya terhadap layanan akademik mahasiswa.

3. Operating sistem dari server masih menggunan windows sehingga tidaklah cocok untuk digunakan mengingat masalah security dan juga diakses banyak client sangat lambat.

4. Masih menggunakannya aplikasi siap pakai seperti Microsoft word, excel dalam pembuatan surat menyurat dan tersimpan di komputer masing-masing pegawai sehingga akan mempersulit ketika akan mencari datanya.

\section{Perancangan Pengembangan Infrastruktur}

Untuk mendapatkan hasil yang optimal dalam menjalankan sistem informasi, perlu didukung dari segi infrastruktur yang memadai yaitu jaringan dan 
server yang handal. Perangkat infrastruktur digunakan untuk mendukung operasional sistem informasi agar mudah diakses oleh civitas akademika dan stakeholder Universitas Asahan. Perangkat server yang akan digunakan harus high end memiliki kehandalan dalam melayani sistem Page | 108 informasi dan tidak boleh down.

\section{Perancangan Infrastruktur Server}

Sesuai perkembangan teknologi sekarang ini, server juga mengalami perkembangan yang sangan pesat. Mulai server yang berbentuk tower, rack dan sekarang ini memiliki jenis type blade. Server jenis blade ini memiliki kehandalan dalam melayani sistem informasi yaitu dari aspek compact (meminimalkan kebutuhan space), scalability (kemudahan dalam pengembangan) serta integrated operation (kemudahan dalam pengoperasian dan pengawasan). Selain kehandalan tersebut server type blade dijalankan dengan menggunakan teknologi virtualisasi seperti vmware. Dengan menggunakan teknologi virtualisasi memiliki keuntungan pengurangan biaya invertasi hardware, kemudahan dalam backup dan recovery, kemudahan deployment, kemudahan dalam maintenance dan pengelolaan. Berbeda dengan server tower harus butuh 1 fisik server untuk 1 operating sistem. Penggunaan teknologi virtualisasi untuk type blade ini tidak banyak memakan space ruangan, karena bisa menampung beberapa sistem operasi dan aplikasi dalam satu fisik server. Sehingga dengan keunggulan type blade ini, sangat direkomendasikan untuk pengembangan dari sisi server. Berikut ini adalah rancangan untuk infrastruktur server :

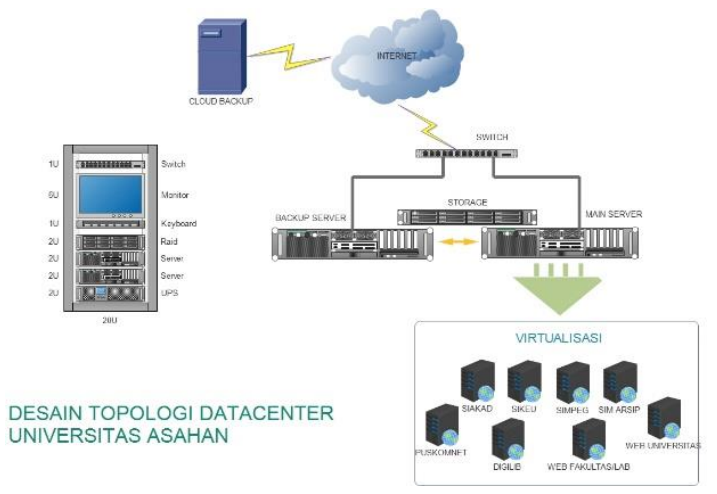

Gbr 4. Rancangan Infrastruktur Server

\section{E. Perancangan Infrastruktur Jaringan}

Infrastruktur jaringan sangat dibutukan untuk pengembangan teknologi informasi dan komunikasi. Perangkat jaringan merupakan media untuk menghubungkan user dengan user lain atau user dengan server. User harus terkoneksi ke jaringan untuk dapat mengakses sistem informasi baik secara intranet maupun internet. Untuk mengalirkan data secara intranet agar tersentralisasi, Universitas Asahan harus memiliki jaringan backbone. Jaringan backbone ini akan menghubungkan antar gedung di lingkungan Universitas Asahan. Teknologi untuk menghubungan jaringan antar gedung menggunakan kabel UTP/STP, wireless (radio) dan juga kabel fiber optic (FO).

Teknologi fiber optic merupakan media kabel yang saat ini sangat baik digunakan. Kabel fiber optic beroperasi dengan kecepatan yang sangat tinggi, dapat mengirimkan sinyal lebih jauh, transfer bandwidth dengan kapasitas besar dan juga merupakan material yang tahan lama. Perencanaan kabel fiber optic di Universitas Negeri Medan menggunakan topologi ring, dimana keunggulan topologi ini akan membuat jalur backup ketika pada salah satu titik mati maka akan melewati jalur yang aktif. Berikut adalah perancangan untuk jaringan backbone Universitas Asahan.

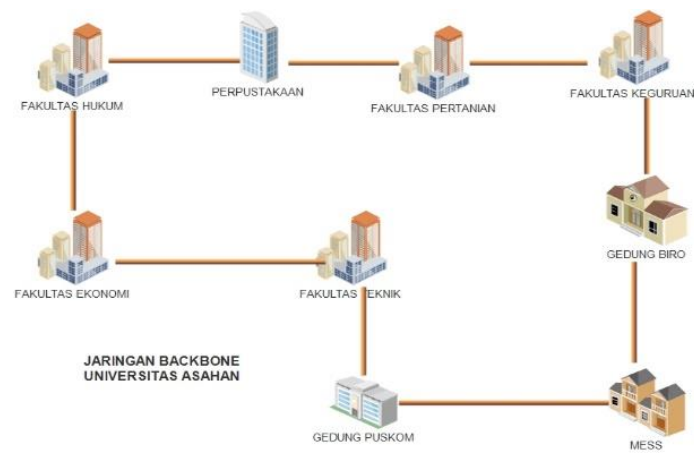

Gbr 5. Jaringan backbone FO Universitas Asahan

Pada jaringan lokal tiap gedung untuk menghubungkan antar komputer menggunakan kabel UTP. Akses user dari laptop menggunakan wireless access point untuk tiap titik gedung. Berikut ilustrasi untuk perancangan jaringan lokal tiap gedung.

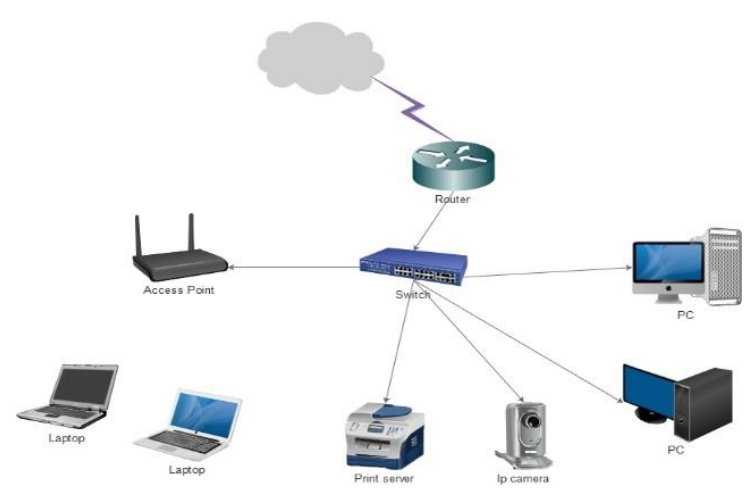

Gbr 6. Perancangan jaringan lokal tiap gedung

Pengembangan infrastruktur server dan jaringan secara garis besar dapat digambarkan sebagai berikut : 
Page | 109

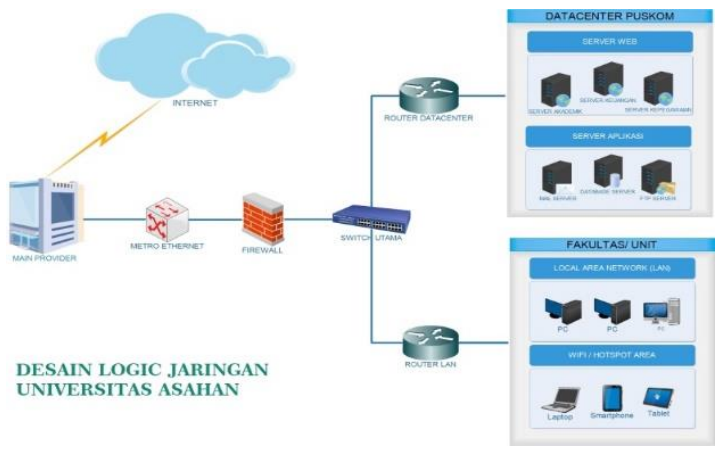

Gbr 7. Topologi Grand Desain Pengembangan TIK Universitas Asahan

\section{F. Perancangan Sistem Informasi Universitas} Asahan

Website Universitas Asahan yaitu una.ac.id akan mejadi gerbang utama untuk masuk kedalam semua sistem informasi.

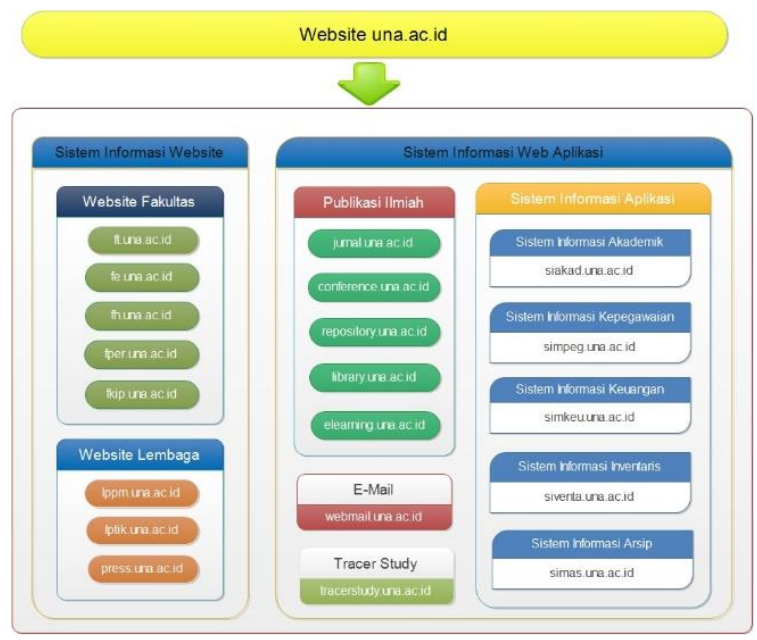

Gbr 8. Perencanaan arsitektur sistem informasi

\section{G. Kebutuhan Pengelola Teknologi Informasi \&} Komunikasi

Dalam upaya menjaga agar perangkat infrastruktur server dan jaringan serta sistem informasi aplikasi di Universitas Asahan dapat tetap beroperasi, diperlukan sumber daya manusia untuk mengelola sistem tersebut. Kebutuhan sumber daya manusia dengan spesialisasi di bidang TIK adalah sebagai berikut.

1. Manager TIK

Seorang manager mampu mengkoordinasikan, monitoring, dan memberikan arahan dalam kegiatan pengoperasian dan pemeliharaan sistem ke anggota TIK.

\section{Sistem Administrator}

Seorang sebagai sistem administrator bertanggung jawab atas pengoperasian dan pemeliharaan aplikasi-aplikasi yang ada di Universitas Asahan agar tetap berjalan dengan lancar.

3. Database Administrator

Seorang database administrator bertanggung jawab atas perancangan, pengelolaan, pengoperasian dan pemeliharaan basis data yang ada di Universitas Asahan.

4. Network Administrator

Seorang network administrator bertanggung jawab atas pemasangan, penggantian, pengoperasian dan pemeliharaan jaringan komputer serta perangkat pendukungnya.

5. Web Administrator

Seorang web administrator bertanggung jawab atas pembuatan, pengembangan, pengoperasian dan pemeliharaan website di lingkungan Universitas Asahan.

\section{Teknisi}

Seorang teknisi bertanggung jawab atas kelancaran operasi perangkat keras komputer dan perangkat lunak di Universitas Asahan.

\section{KESIMPULAN DAN SARAN}

Dari hasil penelitian ini, dapat diambil kesimpulan:

1. Perlunya dilakukan pengembangan Teknologi Informasi dan Komunikasi (TIK) di Universitas Asahan mengingat dari segi infrastruktur dan sistem informasi yang sudah ada belum bisa mengcover layanan yang akan diterapkan demi memberikan layanan yang mudah dan cepat.

2. Penambahan personel bidang IT untuk melakukan perawatan perangkat dalam mendukung layanan sistem informasi yang handal dan peningkatan pengembangan SDM dalam mengembangkan teknologi informasi dan komunikasi.

3. Grand Design atau perancangan dalam penelitian ini dapat dijadikan acuan bagi pengambil kebijakan (pimpinan) serta pelaksana pengelola sistem informasi dan komunikasi, serta seluruh unit kerja di Universitas Asahan dalam rangka meningkatkan dan mendukung proses kerja untuk memberikan layanan yang terbaik kepada civitas akademika dan stakeholder Universitas asahan.

Pengembangan TIK bertujuan untuk mendukung segala proses kegiatan demi tercapainya visi misi Universitas Asahan. Untuk itu agar mendapatkan hasil yang optimal, berikut adalah saran-saran dalam pengembangan TIK:

1. Diperlukan kebijakan pimpinan serta komitmen dari seluruh pihak Universitas Asahan dalam rangka pengendalian dan pengawasan rencana implementasi yang telah ditetapkan agar tidak menjadi bahan literatur saja.

2. Pembentukan unit/ lembaga TIK yang akan membantu melaksanankan pengelolaan IT, memantau serta mengevaluasi perencanaan pengembangan yang telah ditetapkan.

3. Melakukan pengembangan SDM IT secara berkesinambungan agar memiliki kemampuan dalam menangani permasalahan di bidang IT secara update. 
4. Melakukan kerjasama dengan pihak ketiga dalam pengembangan TIK untuk percepatan pencapaian tujuan Universitas Asahan.

5. Melakukan koordinasi, konsolidasi serta sosialisasi kepada seluruh pihak yang terkait untuk mendapatkan hasil yang optimal.

Page | 110

\section{REFERENSI}

[1] Deeson, E, 1991, Dictionary of Information Technology, Harper Collins Publishers, Glasgow, UK

[2] Friedman, T.L., 2006, The World is Flat: The Globalized World in the Twenty-First Century. Penguin Books.

[3] Hartono, Jogiyanto, 2005, Analisis dan Desain Sistem Informasi, Yogyakarta, Andi Offset.

[4] Kristanto, T, 2015, Perencanaan Strategis Sistem Informasi Dan Teknologi Informasi Pada PT. Adira Dinamika Multi Finance, Seminar Nasional Sistem Informasi Indonesia, 2-3 November.

[5] Martin, J., 1990, Information Engineering (Book II, Planning and Analysis). Prentice-Hall.

[6] Nugroho, L.E., 2009, Pemanfaatan Teknologi Informasi dan Komunikasi di Perguruan Tinggi, Yogyakarta, Prajnya Media.

[7] Oetomo, B.S.D., 2006, Perencanaan dan Pembangunan Sistem Informasi, Yogyakarta, Andi Publisher.

[8] Yudhistyra, W.I \& Nugroho, E, 2014, Lima Metode Perencanaan Strategis Sistem Informasi Dan Teknologi Informasi Untuk Pengembangan E-Government, Seminar Nasional Teknologi Informasi dan Komunikasi, Yogyakarta, 15 Maret. 